Penultimate version. June 2011.

Final version published In L. Radoilska (ed.), Autonomy and Mental Disorder (OUP, 2012), pp. 44-74

\title{
THREE CHALLENGES FROM DELUSION FOR THEORIES OF AUTONOMY
}

K.W.M. (Bill) Fulford and Lubomira Radoilska

\section{Introduction}

The main ambition of this chapter is to identify and explore a series of challenges that the phenomenology of delusions poses to our systematic thinking about autonomy. For the sake of the argument, we shall understand autonomy in terms of intentional agency over time (see, for example, Bratman 2007) and will not expand on the possible interactions between this and alternative conceptions, which either take an ahistorical perspective and define autonomy as a distinctive relationship to one's motives at the time of action (Frankfurt 1971), or integrate further criteria, such as responsiveness to (good) reasons (Watson 1975) or accordance with particular values (Hill 1991). ${ }^{1}$ An implication of this methodological choice is that the challenges at issue will have no immediate bearing to emancipatory accounts which define autonomy as a particular social-relational status and therefore have no apparent reason to take delusions as likely failures of autonomy per se, independently of specific institutional contexts (Mackenzie and Stoljar 2000). ${ }^{2}$ In other words, the following discussion is primarily aimed at theories which conceive autonomy as an agency rather than a status concept. ${ }^{3}$ The central claim is that in order to avoid circularity, such theories should be able to address the subsequent challenges from delusion. This becomes clear if we consider the compelling

\footnotetext{
${ }^{1}$ For a comprehensive analysis of these alternatives, see Buss (2008).

${ }^{2}$ This is because such accounts take interpersonal dynamics to be a constitutive part rather than a circumstance only of autonomy. A partial parallel from the phenomenology of delusion is folie à deux in which people living with someone who has delusions (for example within a family) get caught up in their delusional world but only so long as they remain in close and largely exclusive proximity with the person concerned (eg Gelder, Mayou and Cohen 2001, p. 394).

${ }^{3}$ See the Introduction to the volume, $\mathrm{p} . .$.
} 
intuition according to which 'insanity' is an obvious case where autonomy as specified above has broken down (see, in particular, Wolf 1987). What seems to be implied in it however is that 'insanity' is definable independently of whether it compromises autonomy or not. Psychosis as a central mental disorder and delusion, its central symptom seem to provide the required theoretical leverage. The thought is that, unless delusion is conceived as theoretically independent from autonomy, we would end up with a vicious circle: defining 'insanity' as lack of autonomy and then turning back to clarifying autonomy as a state where autonomy is not lacking.

Yet, as we shall argue drawing on Fulford $(1989)^{4}$ the following challenges from delusion suggest that delusions are implicitly understood in terms of various kinds of breakdowns of intentional agency. ${ }^{5}$ Hence, in order to avoid circularity both in defining autonomy and delusions, we need to explicitly address the putative failures of autonomy as presented by the logical topography of delusions, encompassing: their centrality (Challenge 1), their diverse logical range (Challenge 2), and non-pathological instances (Challenge 3). We take these challenges in turn, first setting out and illustrating the relevant features of delusions and then expanding on the implications for theories of autonomy. We conclude by spelling out several caveats that emerge from the discussion and briefly indicating the relevance of the analysis to contemporary policy and practice in mental health.

\subsection{The Centrality of Delusions}

Our first challenge from delusions for theories of autonomy is to address their central legal and ethical significance consistently with their correspondingly central place among other kinds of

\footnotetext{
${ }^{4}$ Fulford (1989) develops an agentic account of the experience of illness in general and of mental illness in particular. This account is further developed in a number of publications, including Fulford (1996) and (1998). Many of the cases described in this chapter are derived from these sources (see Acknowledgements).

${ }^{5}$ See however chapter 5 in this volume, where Bortlotti et al. discuss possible cases of delusions which enhance rather than undermine intentional agency.
} 
psychopathology. In this section we fill out this challenge with an illustrative series of brief case examples starting with the central place of delusions in the map of mental disorders.

\section{The Central Psychopathological Significance of Delusions}

Delusions are the paradigm symptoms of the most serious forms of mental disorder, the psychotic disorders. These disorders include both organic psychoses such as the dementias and other conditions caused by gross pathology affecting the brain (brain tumours, brain infections etc) and non-organic or, as they are called 'functional' psychoses, such as schizophrenia and the affective psychoses (including hypomania, some forms of depression, and bipolar disorder). We will be giving examples of these and of a variety of other disorders in the course of this chapter. As these examples will illustrate, the psychoses as a whole are characterised by the presence of delusions and of related symptoms, such as hallucinations.

Psychotic disorders (and with them delusions) are the most serious kinds of mental disorder in two senses, contingent and constitutive. Contingently, the psychotic disorders carry the highest risk of premature death (by suicide or, far more rarely, homicide). Constitutively, psychotic disorders are the most serious mental disorders in the sense that the delusions and related symptoms by which they are defined are in turn characterised by a particularly profound disturbance of rationality called in descriptive psychopathology, 'loss of insight'.

Like many other psychopathological concepts, psychotic loss of insight, although identifiable with a high degree of reliability in the form of delusions and related symptoms (Wing, Cooper and Sartorius 1974), remains a much contested concept (Lewis 1934; Perkins and Moodley 1993; Amador and David 2004). Essentially, what loss of insight means in this context is that people with psychotic disorders (characteristically) fail to recognise that there is anything (mentally) wrong with them. We can see this by comparing the delusions of guilt arising typically in people with severe depression with the obsessions of guilt that occur in people with obsessive-compulsive disorders. 
Case 1: Delusions of guilt in depressive disorder - Mr. S.D., 50-year old shop keeper

Mr. SD went to see his Family Doctor asking for "something to help me sleep". He looked depressed however and he had 'biological' symptoms (early waking, weight loss and fixed diurnal variation of mood) consistent with a serious form of depressive illness. Questioned further about why he was not sleeping, he was initially reticent but finally admitted that he was worried sick with guilt because he was responsible for causing the (then) recent war in the Balkans. Asked how he (a local shop keeper) could be responsible for what was going on in the Balkans he turned away saying in a quiet voice "you know" and then refused to talk about it further.

Case 2: Obsessions of guilt in obsessive-compulsive disorder - Mr. O.C., Age 27, Solicitor's Clerk

Mr. OC was referred by his GP to a psychiatrist with a three-year history of progressive slowness. He had a recent history of moderate depression and anxiety following suspension from his job (as a result of his increasing failure to get through his work) but was otherwise well and showed no neurological signs (for example of Parkinsonism). The problem he said was that he had been experiencing increasingly intrusive feelings of guilt combined with compulsive checking (it took him for example often twenty minutes to leave his house because of repeated urges to return to check that he had locked the door). He was unable to resist these urges even though he regarded them as "completely ridiculous" and said that he knew perfectly well that he had nothing to feel guilty about "any more than the next man".

In both these cases the person concerned was troubled by what most people would regard as irrational feelings of guilt. Mr SD (Case 1) however, with his delusions of guilt, really believed he was guilty of causing a war and he rejected attempts to reassure him (we return to the features of delusion below under Challenge 2). Mr OC (Case 2), by contrast, with his obsessions of guilt, recognised that his feelings of guilt were irrational (he described them as "completely ridiculous") and he resisted them albeit unsuccessfully (an obsession is like a bad case of getting a tune 'stuck in your head' and a 
compulsion is its behavioural counterpart - as in this case with Mr OC repeatedly returning to check he had locked his front door).

Mr OC (Case 2) then (with obsessions of guilt) had preserved insight: he recognised along with everyone else that his feelings of guilt though persistent and intrusive were irrational and he asked for help because there was something (mentally) wrong with him. Mr SD (Case 1) however (with delusions of guilt) had 'lost insight': far from recognising that there w as anything (mentally) wrong with him he believed that what was wrong was what he had done (caused a war) and for this he felt (justifiably) guilty.

\section{The Central Legal and Ethical Significance of Delusions}

Both senses in which psychotic disorders are serious disorders are relevant to their central legal and ethical significance. The contingently increased risks (to the person themselves and to others) with which the psychotic disorders are associated mean that the stakes are high in managing them. A laissez faire attitude won't do. Decisions have to be made. But the 'loss of insight' by which delusions and related psychotic symptoms are defined carries with it the implication that those concerned are not capable of making decisions for themselves in a fully autonomous way. The following two cases illustrate the consequences of this for the status of psychotic disorders respectively as excusing conditions in law and as conditions justifying the use of involuntary psychiatric treatment.

\section{Case 3: Not guilty by reason of insanity - Daniel McNaughton}

On January $20^{\text {th }} 1843$ in the Charing Cross area of London Daniel McNaughton was arrested by a police constable, James Silver, who witnessed him firing a pistol into the back of Edward Drummond who died a few days later. McNaughton was accordingly arraigned on a charge of murder. However, it soon transpired that McNaughton killed Drummond, the Prime Minister's Secretary by mistake for the Prime Minister, under the delusion that the government was persecuting him. When he came to 
trial his council, Alexander Cockburn, argued that although McNaughton had indeed killed Drummond he was "... the victim of a fierce and fearful delusion, which, after the intellect has become diseased, the moral sense broken down, and self-control destroyed, has led him on to the perpetration of the crime with which he now stands charged." The argument was successful. The jury found McNaughton 'not guilty, by reason of insanity' and instead of being hung as a murderer he was admitted as a patient to Bethlehem Hospital.

This vignette is based on a classic nineteenth century case from which the eponymous McNaughton Rules defining the grounds for the 'insanity defence' in England are derived (8 ER 718, [1843] UKHL J16). ${ }^{6}$ The vignette illustrates the intuitive link between delusion as the defining symptom of what we would now call a psychotic disorder and the legal intuition that disorders of this kind amount not merely to mitigating factors, such as 'guilty but under duress' but to a full-blown legal excuse as 'not guilty (at all) by reason of insanity'.

The 'insanity defence', as it is nowadays called, builds on a long history: the intuition that people who are insane are not responsible for their actions and hence that they are 'mad not bad' dates back to pre-classical times and is evident in a wide variety of both Western and non-Western cultures (Robinson 1996). A similar intuition underpins the central place of delusion-defined psychotic disorders in involuntary treatment.

Case 4: Justified involuntary psychiatric treatment - Mr AB, age 48, Bank Manager

Mr AB was brought into casualty by his wife complaining of head and facial pains. His wife however explained to the casualty officer that the reason she had persuaded her husband to come to casualty was because she believed he was becoming depressed. This was not the first time and she recognised the warning signs. When her husband gets depressed "he always imagines he has some dreadful

\footnotetext{
${ }^{6}$ Further accepted spellings include: McNaughten and M'Naughten (see West and Walk 1977).
} 
disease" and on one occasion he had made a sudden and nearly successful attempt to kill himself. Mr $A B$ certainly looked depressed to the casualty officer although he denied this. On further questioning Mr AB said that "there was no point in all this because he had a brain tumour and was dying". After examining him carefully, the casualty officer explained to $\mathrm{Mr} A B$ that he had found no signs of a brain tumour but that he believed $M r A B$ was becoming depressed again and that he needed to be in hospital for a while so that they could go into everything properly. $\mathrm{Mr}$ AB reacted angrily to this saying that he had agreed to come to casualty only so that he could get "something stronger for the pain". He remained adamant that he would not come into hospital and, given the clear risk of suicide, he was admitted as an involuntary patient under the Mental Health Act.

Most administrations around the world have legislation in place that allows people with mental disorders to be admitted to hospital and/or treated against their wishes if this is considered to be necessary in their own interests or for the protection of others. In contrast with the McNaughton rules and other similar criteria for the use of the insanity defence what is meant by mental disorder is generally left essentially undefined in legislation covering involuntary psychiatric treatment (Fulford and Hope 1996). Involuntary treatment could thus in principle be used for anyone with a mental disorder who presents a risk to themselves or others. In practice, though, as in $\mathrm{Mr} A B$ 's case, the use of involuntary treatment is mainly restricted to the psychotic disorders (Sensky, Hughes and Hirsch 1991; Fulford and Hope 1994).

\section{Challenge 1: The Centrality of Delusions}

The first challenge presented by delusion for theories of autonomy is thus to address its autonomy-impairing nature consistently with its central legal/ethical and psychopathological significance as the characteristic symptom of psychotic mental disorders.

\subsection{Autonomy and the Centrality of Delusions}


Drawing on the preceding discussion of the insanity defence and theory and practice of involuntary psychiatric treatment, it is compelling to infer they both presuppose the idea that mental disorder in general and delusions in particular are forms of internal obstacles to autonomy. ${ }^{7}$ In extremis, these obstacles lead to loss of autonomy, where an agent can no longer be treated as the source of at least some of his or her actions. This is particularly clear in the case of the insanity defence understood as grounds for full excuse rather than a mitigating factor. For, in order to make sense of this notion, we have to think of delusion-motivated behaviour as resulting in outcomes or states of affairs that are merely caused by a delusional agent but are not actions attributable to him or her (Davidson 1980).

The underlying intuition could be clarified with reference to Aristotle's account of voluntariness developed in the Nicomachean Ethics $3.1-5 .^{8}$ There, Aristotle contrasts voluntary actions not only with involuntary or coerced ones (external constraint to intentional agency), but also with nonvoluntary actions which although initiated by the agent are not up to him or her (internal constraint to intentional agency). Examples are physiological processes, such as digestion that do not allow for direct volitional control. In contrast, Aristotle shows that choice not only offers unambiguous evidence for the voluntary character of an action but also has significance of its own for the appraisal of the agent's involvement. This suggestion opens up space for an important category of actions which are voluntary but not done out of choice. Instances of weakness of will offer the paradigm for this kind of behaviour within the original Aristotelian framework.

Following this line of thought, we are able to explain the distinction between compulsion- and addiction-motivated behaviours which could allow for mitigation but not full excuse, on the one hand, and on the other, delusion-motivated behaviours which as outlined earlier are eligible for full excuse (Morse 2000; Watson 1999). Whilst the former class of behaviours undermine intentional agency over

\footnotetext{
${ }^{7}$ This notion builds on the distinction between internal and external obstacles to freedom which Feinberg (1980) sets apart from the distinction between positive and negative obstacles to freedom or, obstacles to positive and negative freedom respectively that was originally set out by Berlin (1958).

${ }^{8}$ For a discussion of this notion of voluntariness within the context of Aristotle's philosophy and its relevance to current debates in theory of action, see Radoilska (2007, pp. 153-290).
} 
time but are compatible with voluntary individual actions, the latter seem to exhibit a deeper mismatch between effective intentions and resulting actions which locates them at the margins of voluntariness and beyond.

The contrast with addiction and compulsion indicates that the centrality of delusions has to do with the idea of a breakdown of rather than mere impediment to intentional agency and confirms the initial account in terms of internal obstacles to autonomy. However, as soon as we take into consideration the implicit social context of human action, it becomes apparent that the idea of delusions as internal obstacles to autonomy could provide a vehicle for oppression from outside. For it is open to misuse as a putative rationale for interventions limiting a person's negative freedom whilst at the same time concealing the restrictive or, liberty-diminishing character of these interventions. ${ }^{9}$ Berlin's critique of positive freedom illustrates well the underlying concern:

"The perils of using organic metaphors to justify the coercion of some men by others in order to raise them to a "higher" level of freedom have often been pointed out. But what gives such plausibility as it has to this kind of language is that we recognise that it is possible, and at times justifiable, to coerce men in the name of some goal... This renders it easy for me to conceive of myself as coercing others for their own sake, in their, not my, interest. I am then claiming that I know what they truly need better than they know it themselves. What, at most, this entails is that they would not resist me if they were rational and as wise as I and understood their interests as I do. But I may go on to claim a good deal more than this. I may declare that they are actually aiming at what in their benighted state they consciously resist, because there exists within them an occult entity - their latent rational will, or their "true" purpose - and that this entity, although it is belied by all that they overtly feel and do and say, is their "real" self, of which the poor empirical self in space and time may know nothing or little; and that this inner spirit is the only self that deserves to have its wishes taken into account. Once I take this view, I am in a position to ignore the actual wishes of men or societies, to bully, oppress, torture them in the name, and on behalf, of their "real" selves..."

\footnotetext{
${ }^{9}$ See note 7 above. We return to this issue in sections 2.2 and 3.3 below, with reference to the notions of objectivity as non-arbitrariness and agential success.
} 
(1958, pp. 179-180)

This concern could provide a plausible motivation for attempts to define delusions as involving some form of cognitive impairment instead of a breakdown of intentional agency. As we note under the second challenge below, much empirical research effort has gone into attempts (thus far inconclusive) to identify one or more particular kinds of cognitive impairment specific to delusion. An account of delusions in terms of cognitive malfunctioning (if such were to prove possible) would apparently warrant the kind of theoretical independence from an implicit conception of autonomy brought up in the Introduction. In turn, this would arguably help construe a notion of delusion as an internal obstacle to autonomy that is resistant to coercive uses like that identified in the quotation above.

The appeal of this approach stems from a particular understanding of cognitive performances as objectively measurable and, in this respect, safer to assess than other aspects of the life of the mind, deemed to be merely subjective and, therefore, arbitrary. As we note in the next section, Anthony Flew (1973) relied on just this kind of supposed objectivity in his account of delusion as an excuse in law. However, even if we assume that this way of thinking about cognition is correct, it cannot help avoid the intuition that delusions are breakdowns of intentional agency. This becomes clear, if we take into consideration recent work in virtue epistemology the central claim of which is that knowledge is an apt, creditable performance (Greco 2003; Sosa 2007; Zagzebski 2001). This analysis clarifies and expands upon our ordinary intuitions, according to which cognitive tasks are something we do, a category of actions subject to appraisals to which mere physiological processes, such as digestion are not. Following this line of thought, it is persuasive to interpret even the simplest cases of cognition where we merely 'get things right' as instances of intentional agency (Radoilska 2010). Therefore, even if delusions could be defined as cognitive failures, this would not get us away from the conclusion that they present breakdowns of intentional agency but merely specify where these breakdowns are likely to occur. At all events, the significance of intentional agency for understanding delusions becomes even clearer if we look in a little more detail at just what exactly delusions are. This brings us to our second challenge. 
Textbook definitions of delusion often take them to be a particular kind of false belief. For instance, the Encyclopedic Dictionary of Psychology defines delusion as:

“... a false belief, held despite evidence to the contrary, and one which is not explicable in terms of the patient's educational and cultural background. It is held with complete conviction and cannot be shaken by argument."

(Harré and Lamb 1987, p. 142)

Delusion as False Belief

This way of defining delusions certainly covers many instances. Here is an example from a person with schizophrenia, though similar delusions may occur in other psychotic disorders.

Case 5: Thought insertion in schizophrenia - Mr. S., aged 18, student

$M r S$ was admitted as an emergency from the college where he was a student. The story was that he had been behaving in what his friends and tutors regarded as an increasingly odd way. He had started to accuse people of talking about him and had taken to wandering about the university playing fields on his own apparently talking to himself. He told the admitting doctor that people were getting at him. It was not anyone at the university however. The problem was that Mike Yarwood (a well known popular entertainer at the time) was 'getting into' his thinking. Mr S became angry and tearful as he tried to describe this. "My mind is not my own anymore. Thoughts come into my head but they are not my thoughts. It is this Mike Yarwood using my mind for his thinking. It's like I'm just a receiving station for his thoughts." 
To all appearances Mr S's belief that anyone could be using his mind for his thinking in this way is clearly false and as the standard definition further requires, it is a culturally atypical belief which (on further questioning ) proved to be resistant to argument and appeals to evidence. The evident falsity of this and other delusions furthermore ties in with their legal and ethical significance as outlined under Challenge 1. For instance, Flew (1973) argued that the objective falsity of delusions is the one sure defence against the (ab)use of psychiatric authority for the sake of social control rather than medical treatment.

The problem though is that the standard definition although indeed covering some kinds of delusion is very far from covering them all. In the first place, many (perhaps most) delusions are not culturally atypical: delusions of guilt for example as in Case 1 above are culturally consonant as are other common delusions (Mr AB's hypochondriacal delusion of brain cancer in Case 4 is a further example). Then again, the resistance to argument and appeals to evidence shown by delusions are features also of other strongly held but non-delusional beliefs (political and religious beliefs, for example). Worse still though, from the perspective of the standard definition, delusions may not even be false beliefs at all, at least not in the 'objectively false' sense required by Flew.

\section{Delusion as True Belief}

Case 6: Othello Syndrome - Mr. A., Age 47, Publican

Mr. A was seen by his general practitioner initially because his wife was depressed. Mr. A. however had symptoms of his own: he complained of anxiety and impotence and his GP suspected that he was drinking far more than was good for him. Some way into the interview, Mr. A. suddenly announced that the real problem behind all his difficulties was that his wife was 'a tart'. Once started, he went on at length about her infidelity, drawing on a wide range of evidence, some of it bizarre (that she did her washing on a different day; that the pattern of cars parked in the street had changed). A subsequent psychiatric opinion confirmed the diagnosis of Othello syndrome. The Othello syndrome is 
defined by the presence of delusions of infidelity. Neither the GP nor the psychiatrist were in any doubt that Mr A had delusions of infidelity. Yet both knew at the time they made their diagnosis of Othello Syndrome that Mrs A had become depressed following the break-up of an affair.

Notice then, that this is not a case of a delusion that turns out to be true as, for example, a patient with delusions of persecution who later turns out to have been persecuted. In Mr A's case the diagnosis of Othello syndrome based on delusions of infidelity was made notwithstanding the fact that those making the diagnosis were aware at the time they made the diagnosis that Mr A's beliefs far from being false were as to the essential fact true.

That delusions may be true beliefs in this sense was pointed out many years ago in a series of detailed case reports of cases of the Othello syndrome (Shepherd 1961). But the logical point that delusions are not essentially false beliefs as to matters of fact is shown perhaps even more decisively by the occasional variant of hypochondriacal delusion, the paradoxical delusion of mental illness.

\section{$\underline{\text { Paradoxical delusion of mental illness }}$}

Case 7: Hypochondriacal delusion of mental illness - Mr. M I, age 40, labourer

Mr MI was brought to casualty by ambulance following an overdose. He had tried to kill himself, he said, because he was mentally ill and people who are mentally ill get 'put away'. He was seen by an experienced duty psychiatrist who confirmed a diagnosis of hypochondriacal disorder with delusions of mental illness.

If delusions really were essentially false beliefs, then Mr MI's delusion of mental illness would be a belief that if false would be true and if true would be false. Mr MI's diagnosis would thus have been strictly un-decidable. Yet there was no doubt about the diagnosis in the minds of those who saw $\mathrm{Mr}$ MI. Indeed so clear were they that he was deluded they would have treated him under the Mental 
Health Act had he not accepted ordinary reassurance that people who were mentally ill did not get 'put away' and was thus no longer considered to be at risk of suicide.

\section{Delusions as Value Judgements}

Cases of delusions as true beliefs are unusual (though no less conceptually significant for that). Mr. MI's story is not a philosophical thought experiment but rather based on the story of a (biographically disguised) real patient. There is though a further kind of delusion that runs counter to the false belief of the standard definition and that is entirely commonplace, namely evaluative delusions (Fulford 1991). One example of such a delusion is the evaluative delusion of guilt. Delusions of guilt may take the form of beliefs as to matters of fact. We had an example of such a delusion with Mr SD in Case 1: Mr SD you will recall thought he was responsible for starting a war. But delusions of guilt may also take the form of value judgements.

Case 8: Delusions of guilt (negative evaluation) - Mr. E D, age 40, Postman

Mr ED was seen at a local psychiatric hospital on a Monday evening as an emergency admission from his GP. The story was that he had become increasingly depressed in the course of the preceding few weeks with a sudden deterioration in his condition over the weekend. The admitting doctor noted severely depressed affect and Mr ED's partner confirmed that he had been sleeping badly and had lost weight. When asked if anything particular had happened over the weekend Mr ED became tearful explaining that he had forgotten to give his children their pocket money. His partner confirmed that this was so but added that he seemed to have gone "completely over the top about it". He seemed to think that it was "some terrible sin", "going on about being useless as a Dad", and, which really frightened her, saying that "they would all be better off if he was dead".

The delusional content of Mr ED's thinking in this case thus differs critically from that of Mr SD in Case 1 above. Mr. SD (factual delusion) delusionally believed that he had caused a war and felt 
(justifiably) guilty as a consequence. Mr ED (evaluative delusion) had forgotten to give his children their pocket money and it was the way he evaluated this (as a deeply wicked sin, etc) that was delusional.

Delusions may also take the form of positive value judgements notably in hypomania (the elevated mood counterpart of depression). The following case illustrates how factual and evaluative delusions of grandeur may often be combined in this condition.

Case 9: Grandiose delusions (positive evaluation) - Miss $H$ M, age 25, a novice nun

Miss $H M$ was brought by two of her superiors for an urgent outpatient appointment. The story was that she had started to show bizarre and sexually disinhibited behaviour that was completely uncharacteristic of her and that they were unable to contain. She had not been sleeping. She showed pressure of speech (ideas rushing out one after the other) and became irritable when questioned about her behaviour. She was she said Mary Magdalene and was trying to do God's work. She also had "all this poetry to write". The nuns who came with her reported that she believed she was writing a great mystical text but that her poetry, although showing some imaginative 'flashes', was rambling and largely incoherent.

\section{Different logic, same practice}

The gap between the standard definition of delusion as a false belief and the actual range of logical forms of delusion that we find in practice could thus hardly be more dramatic. Delusions as our examples illustrate may certainly take the form of false beliefs; but they may also take the form of true beliefs; and they may not be beliefs at all at least as to matters of fact, but value judgements, negative and/or positive in sign. Delusional value judgements furthermore unlike delusional true beliefs are as we have indicated entirely commonplace. And there is a further twist to the story here in the fact that all these different kinds of delusion have the same implications for practice. A delusion is 
a delusion as it were, regardless of its logical form, when it comes to treatment (Fulford 1989, chapter 10). This extends to the legal and ethical significance of delusions. Mr SD (Case 1) for example with his factual delusions of guilt and Mr ED (Case 8) with his evaluative delusions of guilt would have been equally eligible to have been treated as involuntary patients.

Faced with these difficulties with the standard definition some have sought to define delusion not as a false but as an unfounded belief. ${ }^{10}$ This approach however begs the question 'in what sense are delusions unfounded?' Clearly it is right that in some sense delusional beliefs being irrational beliefs are unfounded beliefs. This is at the heart of the ethical and legal as well as psychopathological significance of delusions. But people with delusions may reason intellectually at a very high level and despite some promising early results and credible ideas for certain kinds of delusion, no disturbances of cognitive functioning unique to and covering the full range of delusions has yet been identified. ${ }^{11}$ We come back then to the question we raised at the end of Challenge 1 as to the precise sense in which psychotic disorders disturb intentional agency over time, but now with the added challenge of accommodating the full range of logical forms of delusion.

\section{Challenge 2: The Logical Range of Delusions}

${ }^{10}$ For example, Gelder, Mayou and Cohen (2001, p. 13) define delusion as “... a belief that is firmly held on inadequate grounds, is not affected by rational argument or evidence to the contrary, and is not a conventional belief that the person might be expected to hold given his educational and cultural background." The authors go on to spell out some of the problems with this definition including the fact that delusions may occasionally not be false beliefs.

${ }^{11}$ Garety (2004) reviews recent psychological theories of delusion including motivational and perceptual as well as cognitive approaches. Martin Davies, Max Coltheart and others (eg Davies and Coltheart 2000; and Davies et al. 2001) have developed fruitful cross-disciplinary approaches to some of the monothematic delusions such as the Capgras syndrome (the delusion of doubles). 
Delusions may take the form of true or false factual beliefs, of positive or negative evaluations, and of the paradoxical delusion of mental illness. The second challenge for theories of autonomy is thus to take into account this logical range consistently with the status of delusion as the paradigm case of autonomy-impairing mental disorder.

\subsection{Autonomy and the Logical Range of Delusions}

The diverse logical types of delusions pose a problem for accounts of delusions in terms of objective falsehood and resistance to facts. Such accounts could be seen as a follow-up of the attempts to confine delusions to problems with cognitive functioning in order to avoid subjectivity. However, the variety of delusions covering both factual inaccuracies and evaluative distortions puts into question the effectiveness of this follow-up strategy. ${ }^{12}$ For it would be able to account only for the former but not the latter cluster of delusions. This is essentially why Fulford (1989), pointing to the parallel between the logical range of delusions and the corresponding logical range of reasons for action, argued for an agentic rather than narrowly cognitivist account of delusions. ${ }^{13}$

We can take this argument still further though in recognising that leaving aside evaluative delusions, even some instances of the latter, factual type of delusion may be difficult to accommodate to an 'objective falsehood' account. Examples include cases, such as the Othello syndrome (Case 6 above) where a delusion is known to be true by those making the diagnosis. This kind of delusions is similar to Gettier cases of true justified belief that nevertheless does not amount to knowledge, to the extent that in order to explain what goes wrong in both instances, we need to tap into richer conceptual resources than the notion of facts or objective reality as being 'out there' independently of our epistemic endeavours (Gettier 1963; Zagzebksi and Fairweather 2001). As indicated in the previous section, virtue epistemology offers the required conceptual resources; however, they lead to re-

\footnotetext{
${ }^{12}$ A related point has been made by Richard Gipps in Gipps and Fulford (2004).

${ }^{13}$ Thus, the reasons we (as agents) give for our actions mirror the logical range of delusions in taking the forms respectively of factual beliefs (true or false) and of value judgements (positive or negative). The parallels here are set out in Fulford (1989, ch. 10).
} 
interpreting cognitive functioning in terms of intentional agency, an outcome that the accounts of delusions at issue apparently aim to avoid.

Where does this leave us with respect to concerns about the coercive potential of an account of delusions in terms of inner obstacles to autonomy? In fact, the diversity of delusions may not be bad news about objectivity, understood as non-arbitrary application of the concept. As pointed out in the context of Challenge 1, the interest of confining delusions to instances of cognitive malfunctioning comes from the prospect of avoiding arbitrariness in defining what counts as a delusion. For arbitrariness could easily lead to employing redress of internal obstacles to autonomy as pretence for introducing external obstacles to it.

This valid concern seems misinterpreted by approaches which present delusions as involving objective falsehood and resistance to facts as opposed to subjective viewpoint and evaluative judgement. The root of the problem is that these approaches do not deliver objectivity as nonarbitrariness which is at the heart of the valid concern about coercion but go after a different kind of objectivity that turns out to be both superfluous and unfit for the task, namely, objectivity as mindindependence. For the sake of clarity, this critical point will be broken down into constitutive steps:

1) It is possible to first merge the two conceptual pairs 'objectivity - subjectivity' and 'fact value' into one, and then redefine the poles of the resulting pair as mutually exclusive, only if it is assumed that objectivity means mind-independence. This is because on alternative conceptions of objectivity, such as non-arbitrariness the expression 'objective value' is not an oxymoron and the predicates 'subjective' and 'objective' could be compatible. ${ }^{14}$

2) Accounts of delusions in terms of objective falsehood and resistance to facts do take objectivity and facts to be on the same side of a conceptual gap, on the other side of which are located subjectivity and values.

3) Hence, these accounts are committed to a conception of objectivity as mind-independence.

\footnotetext{
${ }^{14}$ A more detailed discussion of this point can be found in Radoilska (2007, pp. 39-57). See also Langton (2007); Railton (1995) and Wiggins (1995).
} 
4) This conception of objectivity implies that values are by their very nature outside the realm of objectivity for they do not partake in the 'fabric of the world' (Mackie 1977). Instead, it is up to us to endorse or reject any particular values. Hence, they are bound to remain arbitrary.

5) Another direct implication of defining objectivity as mind-independence is that along with values, mental states as such also fall outside the realm of objectivity. They only make a proper subject of inquiry in so far as they are stripped from their subjectivity and reduced down to underlying physiological processes, which are part of the 'fabric of the world'.

6) As argued above, the task that a quest for objectivity in defining delusions is meant to fulfil is to identify non-arbitrary criteria for the application of this concept. Accounts in terms of objective falsehood and resistance to facts fail to carry out this task. What is more, they implicitly deny its possibility. This is because they posit delusions as objectively inexplicable over and above the cognitive or other physiological malfunctioning that delusions may involve. In other words, by substituting the ideal of objectivity as non-arbitrariness with that of objectivity as mind-independence, some accounts of delusion deprive themselves of means to investigate the putative breakdowns of intentional agency which are central aspect of the phenomenology of delusions. For such accounts end up obfuscating the very idea of intentional agency. ${ }^{15}$

An important consequence of this analysis is the acknowledgement that the logical diversity of delusions does not pose a greater challenge to our systematic thinking because some delusions have evaluative rather than factual content. For, as outlined earlier, either would be just as mysterious if we opt out of the vernacular of intentional agency.

\subsection{Non-pathological delusions}

From everything that we have said under Challenges 1 and 2 it may seem that this third challenge involves a contradiction in terms. How it may be said can delusions be, on the one hand constitutive

${ }^{15}$ Cf. Chapter 2 of this volume, in which Alfred Mele addresses a related confusion in some neuroscience-based arguments for the nonexistence of free will. 
of the paradigmatically autonomy-impairing psychotic mental disorders, and, on the other hand, nonpathological? We will return to 'how?' below. First, as in earlier sections, we will start by letting the stories of real people (one particular person in this instance) speak for themselves.

Case 10 (Part I): Primary delusions-Simon, aged 40, lawyer

Simon was a senior, black, American lawyer from a middle-class, Baptist family. Although not a religious man he had had occasional relatively minor psychic experiences that had led him from time to time to seek the guidance of a professional 'seer'. Otherwise his career and life generally were going well.

Then, out of the blue, he was threatened by a malpractice legal action from a group of his colleagues. Although he claimed to be innocent, mounting a defence would be expensive and hazardous. He responded to this crisis by praying in front of an open bible placed on a small altar that he set up in his front room. After an emotional evening's 'outpouring' he found that wax from two large candles on the altar had run down onto the bible marking out various words and phrases (he called these wax marks 'seals' or 'suns'). He described his experiences thus. "I got up and I saw the seal that was in my father's bible and I called my friend John and I said, you know, 'something remarkable is going on over here.' I think the beauty of it was the specificity by which the sun burned through. It was ... in my mind, a clever play on words."

From this time on, Simon received a complex series of 'revelations' largely conveyed through the images left in melted candle wax. They meant nothing to anyone else including Simon's Baptist friends and family. But for Simon they were clearly representations of biblical symbols particularly from the book of Revelations (the bull, the 24 elders, the arc of the covenant, etc) signifying that "I am the living son of David ... and I'm also a relative of Ishmael and ... of Joseph". He was also the "captain of the guard of Israel". He found this role carried awesome responsibilities: "Sometimes I'm saying - $O$ my God, why did you choose me, and there's no answer to that". His special status 
had the effect of "increasing my own inward sense, wisdom, understanding, and endurance" which would "allow me to do whatever is required in terms of bringing whatever message it is that God wants me to bring". When confronted with scepticism, he said simply: "I don't get upset, because I know within myself, what I know".

Simon's story is one of a number of similar accounts collected by Mike Jackson in a study of the differences between psychosis and spiritual experience (Jackson 1997; Jackson and Fulford 1997). So what should we make of Simon's experiences? Are they delusional?

One way to answer this question is by reference to psychiatry's standard diagnostic tools. Among these, the PSE (Present State Examination) provides a carefully developed diagnostic schedule for identifying key psychiatric symptoms (Wing, Cooper and Sartorius 1974). The PSE covers over a hundred such symptoms including a wide variety of delusions. Among these we find what is called a 'primary delusion' the description of which fits Simon's case like a glove. The PSE defines this as a delusion which is

$" . .$. based upon sensory experiences (delusional perceptions) [Simon's wax seals in this case] in which a patient suddenly becomes convinced that a particular set of events has a special meaning" (Wing, Cooper and Sartorius 1974, pp. 172 - 173)

Simon therefore according to best practice in psychiatric diagnosis has a primary delusion. But delusions as we indicated above are the constitutive symptoms of psychotic mental disorders. Correspondingly then, when we turn to the World Health Organisation's International Classification of Diseases (ICD), we find that such delusions persisting, as in Simon's case, for longer than a month are sufficient for a diagnosis of a psychotic disorder, including schizophrenia, hypomania, etc. (1992, p 88). 
QED, then, you may think. But this is where our third challenge bites. For Simon showed no signs of being ill still less of suffering from a severe psychotic illness.

\section{Case 10 (Part II): Non-delusional primary delusions?}

Simon's 'seals' as we indicated empowered him. But more than this they guided him first to take on his accusers and then over how to run his case (as a lawyer he defended himself). To cut a long story short the result was that he won his case (it was shown to be a racially motivated attempt to undermine his growing practice), his reputation as a lawyer was further enhanced, he went on to make a great deal of money, and when last heard of was setting up a trust fund to support research not on schizophrenia but on religious experience.

Presented with the outcomes of Simon's story psychiatrists (and others) have a split reaction. Some insist that Simon's story should be understood as an illness albeit one that in his case ran an unusually benign course. Others take Simon's story at face value (and as Simon himself took it) as a story of religious (if idiosyncratic) experience. Both interpretations are possible. As to the illness interpretation, Simon would have strongly rejected the idea that his experiences, which were so formative in his life, should be written off as some kind of pathology, however 'benign'. Such a rejection, though, of there being 'something (mentally) wrong', is, you will recall from Challenge 1, fully consistent with the 'loss of insight' by which delusions are characterised.

As to the religious experience interpretation of Simon's story on the other hand, there is support for this from a perhaps surprising quarter, the main competitor to the ICD diagnostic classification, the American Psychiatric Association's Diagnostic and Statistical Manual (2000). The DSM, as it is called, is closely similar to the ICD in the symptoms, including primary delusions that it takes to be diagnostically significant. But the DSM differs from the ICD in requiring in addition to symptomatic criteria for psychiatric diagnosis what it calls 'criteria of clinical significance'. Simon in experiencing primary delusions satisfies the DSM's symptomatic criteria for a diagnosis of schizophrenia or other 
psychotic disorder just as he does the corresponding criteria in the ICD. But it turns out that he fails to satisfy the DSM's additional criterion of clinical significance. The so-called Criterion B for schizophrenia reads as follows:

"Social/occupational dysfunction: For a significant portion of the time since the onset of the disturbance, one or more major areas of functioning such as work, interpersonal relations, or selfcare are markedly below the level achieved prior to the onset ..."

(American Psychiatric Association 2000, p. 285)

Criterion B then, is as it says a criterion of 'social/occupational dysfunction'. For a diagnosis of schizophrenia in the DSM Simon must show not only primary delusions or other relevant symptoms but also deterioration in his social and/or occupational functioning. His story is silent on his social functioning. But it is clear that his occupational functioning far from deteriorating was actually enhanced.

\section{Delusions normal and pathological}

How should this be understood? With challenges 1 and 2 we set up delusion as the constitutive symptom of the paradigmatically autonomy-impairing psychotic mental disorders. Challenge 3 now suggests that delusions although indeed sometimes symptoms of mental disorder may at other times not be pathological at all. This suggestion moreover comes not from a critique of delusion that is external to psychiatry but from the story of a real person (biographically disguised as Simon) interpreted through one of psychiatry's most influential diagnostic manuals, the DSM.

Simon's story is not a one off exception that proves the rule. It is as we said earlier one of a series of similar stories collected originally by Mike Jackson. Jackson and others have subsequently carried out wider epidemiological studies confirming that non-pathological psychotic experiences are widespread in the general population (Jackson 1997; Johns and Van Os 2001). The British Psychological Society 
has indeed gone on to publish a platform statement arguing that psychotic experiences as such should be regarded as the basis of a problem solving capacity (2000). There are perhaps resonances here of traditionally recognised links between madness and creativity (Jamison 1993). To be clear, there is no suggestion that psychotic disorders are a fiction. Like any other capacity, the capacity for psychotic experience may sometimes 'go wrong'. But there is no necessity here, contingent or analytic. Delusions and other psychotic experiences for all their significance as symptoms of mental disorder may also be not only normal but positively life enhancing.

\section{Challenge 3: Non-pathological delusions}

The third challenge for philosophical theories of autonomy is thus to clarify how pathological (autonomy-impairing) delusions are different from non-pathological (autonomy-preserving) delusions.

\subsection{Autonomy and non-pathological delusions}

Non-pathological delusions offer a critical perspective onto the first two challenges which build upon the idea that there is a strong link between delusions and different kinds of breakdowns of intentional agency. In particular, they prompt us to look again into the notion of internal obstacle to autonomy we introduced earlier. This is not to say that in so far as delusions turn out to be beneficial for a person, they cannot present internal obstacles to his or her autonomy. For good luck is compatible with a breakdown of intentional agency.

This becomes clear if we consider a thought experiment set out by Linda Zagzebski (2001) in which a benign manipulator ensures that a prospective knower believes only truths. In this scenario, the manipulator monitors the belief formation of the manipulated agent and intervenes, unbeknown to her, only if she is on the verge of acquiring a false belief. The prospective knower ends up holding only 
true beliefs. Yet, her epistemic agency is undermined by the implicit manipulation of her reasoning. Hence, fortunate end results could be brought about by internal obstacles to intentional agency. ${ }^{16}$

In light of these observations, it is more promising to interpret the challenge from non-pathological delusions as an indication that there is an implicit success criterion at work in the previous two challenges and in particular that effective intentional agency over time is the reference point when defining what goes wrong with delusions. Having ruled out cases, in which things just happen to work out well for delusional agents, it is important to clarify whether an underlying success criterion adds to the legitimate concerns about coercion we identified earlier or, on the contrary, could help to address them. Practically, it may be thought, a sufficient response to any concerns raised by the recognition of an implicit success criterion is the development of more effective ways of balancing complex and conflicting values in decision making (as in the model of values-based practice ${ }^{17}$ ). But the very effectiveness of this practical move in turn points us back to the need for a more robust theoretical understanding of how values come in to judgements of autonomy if we are to avoid it being used for abusive ends. The following discussion will not aim to provide anything in the way of a comprehensive theory but rather to identify and briefly comment upon three prima facie plausible interpretations of the agential success which seems to distinguish non-pathological delusions from pathological ones: conventionalist, particularist, and universalist.

As its name suggests, the first alternative proposes to construe agential success in conventional terms. To put it crudely, an agent is successful on this view in so far as he or she manages to secure the kind of goods that are generally considered as enviable by his or her society or social group. This interpretation is consistent both with a notion of mental disorder as involving significant impairment of social or occupational functioning and diagnostic guidelines advising to pay particular attention to the cultural backgrounds of prospective psychiatric patients. The plausibility of a conventionalist approach to agential success in the context of delusions stems from its ability to provide an additional perspective onto putative clinical cases. The thought is that this extra viewpoint could act as a

\footnotetext{
${ }^{16}$ This point is developed in more detail in Radoilska (2010).

${ }^{17}$ See for example Fulford, 1994 and Woodbridge and Fulford, 2004 on values-based practice.
} 
corrective to potentially coercive applications of clinical authority in deciding which delusions are pathological. However, the conventionalist interpretation leaves unattended concerns about societal rather than medical arbitrariness in defining mental disorder. In doing so, a conventionalist understanding of agential success may offer a platform for the resentment of majorities by inadvertently allowing them to discredit unpopular conceptions of the good and penalise dissenters. That this is no merely theoretical possibility is indicated by for example attributions of mental disorder to political dissidents on the basis of 'delusions of reconstruction' in the former USSR (Fulford, Smirnov and Snow 1993).

The second, particularist interpretation of agential success could be seen as an improvement on the latter issue. This is because the success criterion it employs is the set of goals that an agent endorses, independently of the ways in which the projects at issue are seen from an observer's perspective. This would be closer to Simon's case. However, both the appeal and the limitations of the particularist approach stem from an instrumental conception of practical rationality, with its strict distinction between facts and values, means and ends (Foot 1972). ${ }^{18}$ Like accounts of delusions in terms of objective falsehood and resistance to facts, the particularist interpretation locates the relevant questions about intentional agency at the level of beliefs and handling of evidence. The crucial question however is not whether they reflect correctly an external reality conceived as independent of the human mind. What matters instead is whether an agent's set of beliefs and overall reasoning promote rather than impede the pursuit of objectives he or she has set for him or herself. An apparent advantage of the particularist interpretation is that the notion of internal obstacle of autonomy becomes directly linked to a fist-person perspective. ${ }^{19}$ This could be seen as a reliable barrier to coercive uses of this notion aiming to impose a third-perspective on delusional experiences as ultimately authoritative. However, this advantage comes at a rather unexpected price: the final ends of action are assigned beyond the confines of practical rationality. In this sense, they are made irrelevant

\footnotetext{
${ }^{18}$ See also Radoilska (2007, pp. 109-128) for a critical analysis.

${ }^{19}$ On the significance of distinguishing first-personal from third-personal considerations about autonomy, see chapter 9 of this volume by Hallvard Lillehammer.
} 
to ascertaining either agential success or possible breakdowns of intentional agency. For these ought to be conceived in purely executive as opposed to evaluative terms ${ }^{20}$ in order to forestall coercive uses of the notion of internal obstacle to autonomy as specified by the particularist strategy. The distinction between the two kinds of failures of intentional agency is helpfully brought out by the following illustration:

"There is no doubt but that there are different kinds of cases of contrary-to reasonness, and not surprisingly it is possible to contravene rationality in more than one way at the same time. I once read of a burglar who was caught because he sat down to watch television in the house he was burgling, thus adding the contrary-to-reasonness of imprudence to that of dishonesty. Because his actions were faulty in that he did not hurry away with the swag, we can say, if we like, that he should have done so."

\section{(Foot 1995, p. 7)}

The particularist interpretation of agential success considers as problematic only the "contrary-toreasonness" due to imprudence or in terms of the distinction we introduced earlier executive rather than evaluative failures of intentional agency. As pointed out at the start of the discussion, this may be considered as an advantage for the particularist strategy since it rules out a moralised account of agential success. In doing so, it seems to avoid the danger of facilitating external obstacles to autonomy under the guise of redressing internal ones. Unfortunately, there is good reason to doubt that this danger has been avoided. By choosing to treat the ultimate ends of action as tangential to a person's success as an agent, the particularist interpretation becomes unable to track down a central case of obstacle to autonomy which has external origins but internal manifestation: the internalisation of oppressive social norms (Stoljar 2000). The underlying worry is that by focusing merely on how an agent carries out his or her plans the particularist interpretation lets inappropriate influences in the formation of these plans to slip under the radar. Yet these kinds of influences grossly undermine a

\footnotetext{
${ }^{20}$ This contrast draws on the distinction between executive and evaluative practical commitment introduced by Mele (1995, p. 71).
} 
person's intentional agency, for the affected plans are not up to him or her in the required sense for voluntariness as spelt out in the context of Challenge 1.

The third, universalist interpretation is in a position to address not only executive, but also evaluative obstacles to autonomy. This is because it conceives agential success as a twofold achievement: not only is an agent's plan brought to fruition, the plan itself also has to be worth undertaking in a sense that cannot be fully reduced to the agent's endorsement. However, the latter requirement seems open to the objection that it peddles a moralised view of intentional agency and could easily serve the purposes of coercion. For if agential success applies to instances where the ends of action are worthwhile, not merely effectively implemented, a third-person or observer's perspective becomes as important as the first-person or agent's perspective.

A possible way of addressing this worry is to impose stringent conditions on the kinds of thirdpersonal considerations that could be given such weight. For instance, it is plausible to argue that nonarbitrary third-personal considerations about agential success should stop at the formal as opposed to substantive features of the plans under consideration. The idea is to be able to locate unobvious obstacles to autonomy, such as self-loathing and related effects of internalised oppression, and to make sure that the plans the agent pursues are sufficiently up to him or her in order to qualify as voluntary. Yet, the underlying theoretical objective cannot be achieved unless the features of a plan for action yield themselves to a neat distinction to formal, on the one hand, and substantive, on the other. In light of our earlier observations about fact and value, and means and ends, there is good reason to doubt that this strategy would be entirely successful. For the kind of voluntariness implicit in the notion of a plan being up to the agent may not be easily separable from a notion of reasonableness. This becomes clear if we take into consideration an intuitive test for discovering whether a particular option has been freely chosen or imposed. In this respect, the inherent choiceworthiness of the option offers just as valuable an indication as the availability of possible alternatives. This outcome sends us back to the initial concern about non-arbitrariness in defining both agential success and possible breakdowns of intentional agency. 


\section{Concluding remarks}

The three challenges that we identified and explored in this chapter point to an inescapable yet elusive association between delusions on the one hand and various kinds of breakdowns of intentional agency on the other. In particular, the centrality of delusions helped clarify both the appeal and the coercive potential of thinking about delusions in terms of internal obstacles to autonomy, in the presence of which an action is no longer up to the agent but merely caused by him or her. In turn, the parallel between the logical diversity of delusions and the corresponding logical diversity of reasons for action led us to the need to distinguish between two separate conceptions of objectivity that may be at work in existing accounts of delusions. This distinction is significant, for it suggests that the difficulty in defining delusions is not due to the evaluative as opposed to factual content of some delusions but to a potentially misleading conception of objectivity as mind-independence. Finally, non-pathological instances of delusions enabled us to put a spotlight on a success condition that is implicit in the notion of a breakdown of intentional agency. Yet, none of the three initially plausible interpretations of agential success that we looked into could satisfy the legitimate ideal of objectivity as nonarbitrariness that emerged from the discussion. This outcome is not entirely aporetic as it opens up a promising line of inquiry for clarifying putative breakdowns of intentional agency within a viable objectivity conception. Such a line of inquiry would both draw critically on the features of delusion and, in turn through such initiatives as values-based practice aim to inform policy and practice relative to this most challenging symptom of mental disorder.

\section{Acknowledgements}

Case 3 (Daniel McNaughton) is based on $R v$ McNaughton [1843] 4 St Pr 847, 8 ER 718 and West and Walk (1977), and Case 10 (Simon) is based on case materials collected by Jackson (1997). The remaining cases, including Case 7 (paradoxical delusion of mental illness) are adapted from examples published in various forms in Fulford (1989, 1991, 1996 and 1998). More detailed accounts of these and other forms of psychopathology, including first personal accounts together with detailed reading guides and philosophical annotations (provided by Richard Gipps) are given in chapter 3 
"Experiences Good and Bad: an introduction to psychopathology, classification, and diagnosis for philosophers" of The Oxford Textbook of Philosophy and Psychiatry by Fulford, Thornton and Graham (2006).

\section{References}

Amador, X.F. and David, A.S. Eds (2004) Insight and Psychosis. 2nd ed. Oxford: Oxford University Press.

American Psychiatric Association (2000) Diagnostic and Statistical Manual of Mental Disorders. Fourth Edition with Text Revision. Washington, DC: American Psychiatric Association.

Aristotle (1995). Nicomachean Ethics. In Barnes, J. (ed.). The Complete Works of Aristotle. Vol.2. Princeton: Princeton University Press; 1729-1867.

Berlin, I. (1958). Two concepts of liberty. In Berlin, I. Liberty (Hardy, H. ed.; 2002). Oxford: Oxford University Press; 166-217.

Bortolotti, L., Cox, R., Broome, M. and Mameli, M. [in this volume]. Rationality and self-knowledge in delusion and confabulation: implications for autonomy as self-governance.

Bratman, M. (2007). Structures of Agency. Oxford: Oxford University Press.

British Psychological Society (2000) Recent Advances in Understanding Mental Illness and Psychotic Experiences. The British Psychological Society, Division of Clinical Psychology, Leicester.

Buss, S. (2008). Personal autonomy. In Zalta, E.N. (ed.) The Stanford Encyclopaedia of Philosophy (Winter 2008 Edition), URL $=<$ http://plato.stanford.edu/entries/personal-autonomy/ $>$.

Davidson, D. (1980). Freedom to act. Repr. in Davidson, D. (2001). Essays on Actions and Events. Oxford: Clarendon Press; 63-81.

Davies, M. and Coltheart, M. (2000) Introduction: pathologies of belief. In Coltheart, M. and Davies, M. (eds). Pathologies of Belief. Oxford: Blackwell; 1-46.

Davies, M., Coltheart, M., Langdon, R., and Breen, N., (2001) Monothematic Delusions: Towards a Two-Factor Account. Philosophy, Psychiatry, \& Psychology 8 (2/3): 133-158. 
Feinberg, J. (1980). Rights, Justice and the Bounds of Liberty: Essays in Social Philosophy. Princeton, Guildford: Princeton University Press; chapter 1 The Idea of a free man.

Flew, A. (1973) Crime or Disease? New York: Barnes and Noble.

Foot, P. (1972). Morality as a system of hypothetical imperatives. Philosophical Review 81: 305-316.

Foot, P. (1995). Does moral subjectivism rest on a mistake? Oxford Journal of Legal Studies 15(1): 114.

Frankfurt, H. (1971). Freedom of the will and the concept of a person. Journal of Philosophy 68(1): $5-20$.

Fulford, K.W.M. (1989) Moral Theory and Medical Practice. Cambridge: Cambridge University Press (repr. 1995; 1999).

Fulford, K.W.M. (1991) Evaluative delusions: their significance for philosophy and psychiatry. British Journal of Psychiatry 159: 108-112 (Suppl. 14: Delusions and Awareness of Reality).

Fulford, K.W.M. (2004) Ten principles of values-based medicine. In Radden, J. (ed.) The Philosophy of Psychiatry: A Companion. New York: Oxford University Press; 205-234.

Fulford, K.W.M. (1996) Value, illness and action: delusions in the new philosophical psychopathology. In Graham G. and Stephens, G.L. (eds). Philosophical Psychopathology Cambridge, MA: MIT Press.

Fulford, K.W.M. ( 1998) Completing Kraepelin's psychopathology: insight, delusion and the phenomenology of illness, chapter 3 in Amador, X. F. and David, A. S. (eds). Insight and Psychosis. $2^{\text {nd }}$ ed. New York and Oxford: Oxford University Press (2004).

Fulford, K.W.M. and Hope, R.A. (1994) Psychiatric ethics: a bioethical ugly duckling? Ch 58 In Gillon, R. and Lloyd, A. (eds.) Principles of Health Care Ethics. Chichester, England: Wiley; 681695. 
Fulford, K.W.M. and Hope, T. (1996) Control and practical experience. In Koch, H.-G., Reiter-Theil, S. and Helmchen, H. (eds.) Informed Consent in Psychiatry: European Perspectives on Ethics, Law and Clinical Practice. Baden-Baden: Nomos; 349-377.

Fulford, K.W.M., Smirnov, A.Y.U. and Snow, E. (1993) Concepts of disease and the abuse of psychiatry in the USSR. British Journal of Psychiatry 162: 801-810.

Fulford, K.W.M., Thornton, T., and Graham, G. (2006). The Oxford Textbook of Philosophy and Psychiatry. Oxford: Oxford University Press.

Garety, P. A, (2004) Insight and Delusions, chapter 4 in Amador, X.F. and David, A.S. (eds). Insight and Psychosis. $2^{\text {nd }}$ ed. Oxford: Oxford University Press.

Gelder, M., Mayou, R., and Cowen, P. (2001) Shorter Oxford Textbook of Psychiatry. $4^{\text {th }}$ ed. Oxford: Oxford University Press.

Gettier, E. (1963). Is justified true belied knowledge? Analysis 23: 121-123.

Gipps, R.G.T., and Fulford, K.W.M. (2004) Understanding the clinical concept of delusion: from an estranged to an engaged epistemology. In Broome, M.R. and Bebbington, P. (eds.) International Review of Psychiatry: Special Issue on the Philosophy of Psychiatry 16(3): 225-235.

Greco, J. (2003). Knowledge as credit for true belief. In DePaul, M. and Zagzebski, L. (eds.), Intellectual Virtue: Perspectives from Ethics and Epistemology. Oxford: Clarendon Press; 111- 34.

Harré, R. and Lamb, R. (eds.) (1987). The Encyclopedic Dictionary of Psychology. Oxford: Blackwell.

Hill, T. E. (1991). Autonomy and Self-Respect. Cambridge: Cambridge University Press.

Jackson, M.C. (1997) Benign schizotypy? The Case of Spiritual Experience. In Claridge, G. S.( ed.) Schizotypy: Relations to Illness and Health. Oxford: Oxford University Press; 227-250.

Jackson, M., and Fulford, K.W.M. (1997). Spiritual experience and psychopathology. Philosophy, Psychiatry, \& Psychology 4(1): 4-66. 
Jamison, K.R. (1993). Touched With Fire: Manic Depressive Illness and the Artistic Temperament. New York: Free Press Paperbacks.

Johns, L.C. and van Os, J. (2001) The Continuity of psychotic experiences in the general population. Clinical Psychology Review 21(8): 1125-1141.

Langton, R. (2007). Objective and unconditioned value. Philosophical Review 116(2): 157-185.

Lewis, A.J. (1934) The psychopathology of insight. British Journal of Medical Psychology 14: 332348.

Lillehammer, H. [in this volume]. Autonomy, value, and the first person.

Mackenzie, C. and Stoljar, N. (eds.) (2000). Relational Autonomy: Feminist Perspectives on Autonomy, Agency and the Social Self. New York: Oxford University Press.

Mackie, J. L. (1977). Ethics: Inventing Right and Wrong. Harmondsworth (NY): Penguin.

Mele, A. (1995). Autonomous Agents. New York: Oxford University Press.

Mele, A. [in this volume]. Autonomy and neuroscience.

Morse, S. (2000). Hooked on hype: addiction and responsibility. Law and Philosophy 19(1): 3-49.

Perkins, R. and Moodley, P. (1993) The arrogance of insight. Psychiatric Bulletin 17: 233-234.

Radoilska, L. (2007). L'Actualité d'Aristote en morale. Paris: Presses Universitaires de France.

Radoilska, L. (2010). An Aristotelian approach to cognitive enhancement. Journal of Value Inquiry 44: $365-375$.

Radoilska, L. [in this volume]. Introduction: personal autonomy, decisional capacity, and mental disorder.

Railton, P. (1995). Subject-ive and Objective. Ratio 8(3): 259-276.

Robinson, D. (1996). Wild Beasts and Idle Humours. Cambridge (Mass): Harvard University Press.

Sensky, T., Hughes, T., and Hirsch, S. (1991). Compulsory psychiatric treatment in the community, Part 1: A Controlled study of compulsory community treatment with extended leave under the mental 
health act: special characteristics of patients treated and impact of treatment, British Journal of Psychiatry 158: 792.

Shepherd, M. (1961). Morbid jealousy: some clinical and social aspects of a psychiatric syndrome, Journal of Mental Science 107: 687-704.

Sosa, E. (2007) A Virtue Epistemology. Vol. 1: Apt Belief and Reflective Knowledge. Oxford: Clarendon Press.

Stoljar, N. (2000). Autonomy and the feminist intuition. In Mackenzie, C. and Stoljar, N. (eds.) Relational Autonomy: Feminist Perspectives on Autonomy, Agency and the Social Self. New York: Oxford University Press; 94-111.

Watson, G. (1975). Free agency. Journal of Philosophy 72(8): 205-220.

Watson, G. (1999). Excusing addiction. Law and Philosophy 18: 589-619.

West, D. J. and Walk, A. (1977). Daniel McNaughton: his Trial and the Aftermath. London: Gaskell Books.

Wiggins, D. (1995). Objective and subjective in ethics with two postscripts about truth. Ratio 8(3): $243-258$.

Wing, J.K., Cooper, J.E. and Sartorius, N. (1974) Measurement and Classification of Psychiatric Symptoms. Cambridge: Cambridge University Press.

Woodbridge, K., and Fulford, K.W.M. (2004) 'Whose Values?' A Workbook for Values-Based Practice in Mental Health Care. London: The Sainsbury Centre for Mental Health.

Wolf, S. (1987). Sanity and the metaphysics of responsibility. Repr. In Watson, G. (ed.). (2003). Free Will. Oxford: Oxford University Press; 372-387.

World Health Organization (1992) The ICD-10 Classification of Mental and Behavioural Disorders: Clinical Descriptions and Diagnostic Guidelines. Geneva: World Health Organization. 
Zagzebski, L. (2001). Must knowers be agents? In Fairweather, A. and Zagzebski, L. (eds.), Virtue Epistemology: Essays on Epistemic Virtue and Responsibility. Oxford: Oxford University Press; 149152.

Zagzebski, L. and Fairweather, A. (2001). Introduction. In Fairweather, A. and Zagzebski, L. (eds.), Virtue Epistemology: Essays on Epistemic Virtue and Responsibility. Oxford: Oxford University Press; 3-15. 